\title{
Endoscopy-assisted magnetic compression anastomosis for rectal anastomotic atresia
}

Magnetic compression anastomosis (MCA) has been used to achieve anastomotic recanalization to treat severe stenosis or atresia of the biliary tract and digestive tract [1-4]. Herein, we report successful recanalization by means of MCA in a case of rectal anastomotic atresia.

A 60-year-old man who had undergone radical resection combined with doublelumen ileostomies for rectal carcinoma 1 year ago, and was scheduled to undergo stoma closure surgery 3 months ago, was admitted to our hospital with anastomotic atresia, where the anastomosis was completely obstructed by regenerated scar tissue. Anastomotic atresia $0.5 \mathrm{~cm}$ in
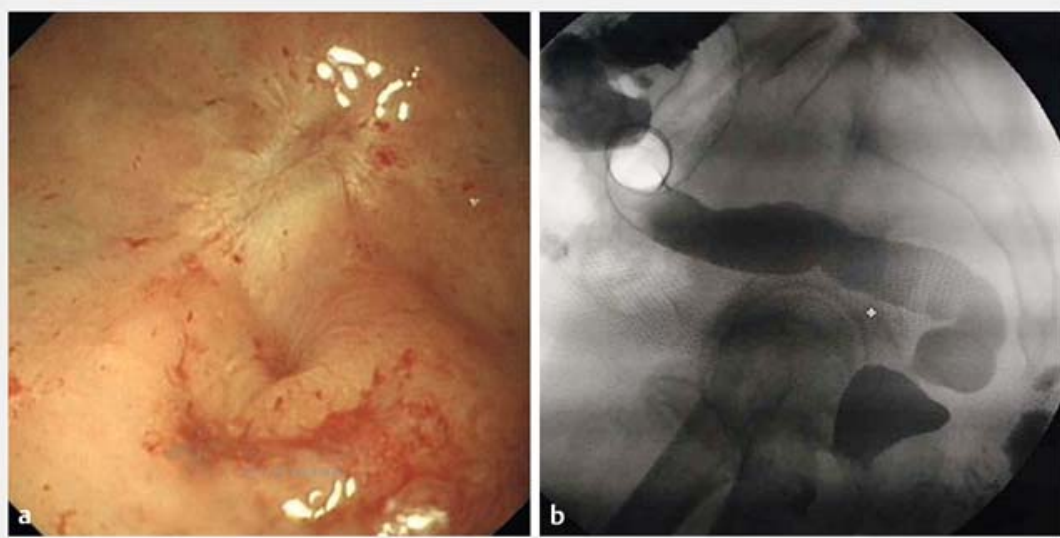

- Fig. 1 Rectal anastomotic atresia $0.5 \mathrm{~cm}$ in length: a colonoscopy, b meglumine diatrizoate radiography.
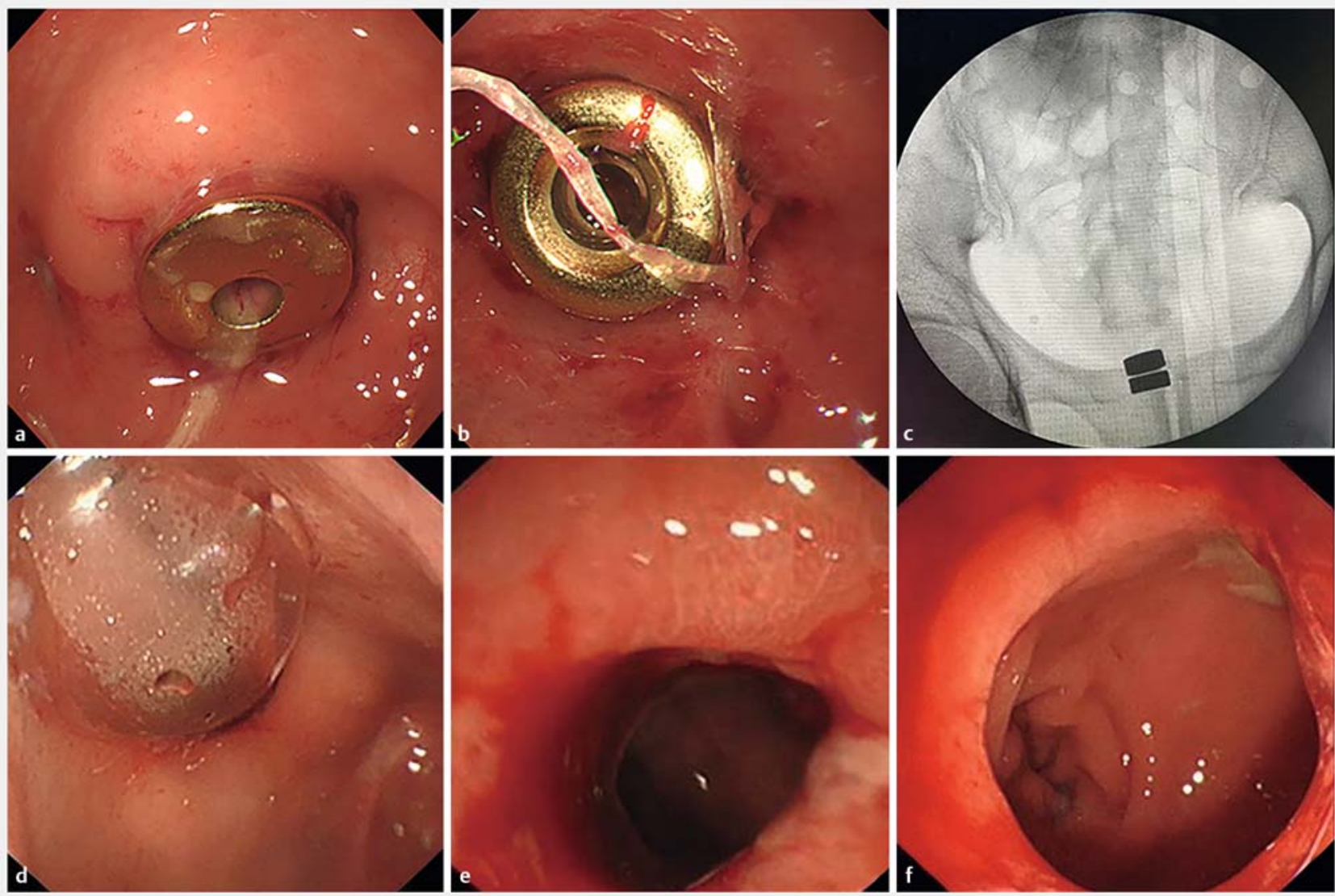

- Fig. 2 Endoscopy-assisted rectal magnetic compression anastomosis and balloon dilatation. a, b Magnetic rings in place: a on the oral side, $\mathbf{b}$ on the anal side. $\mathbf{c}$ C-arm radiography shows the magnetic rings to be well-aligned. $\mathbf{d}$ Balloon dilation. e, $\mathbf{f}$ Anastomotic stoma after dilation. 

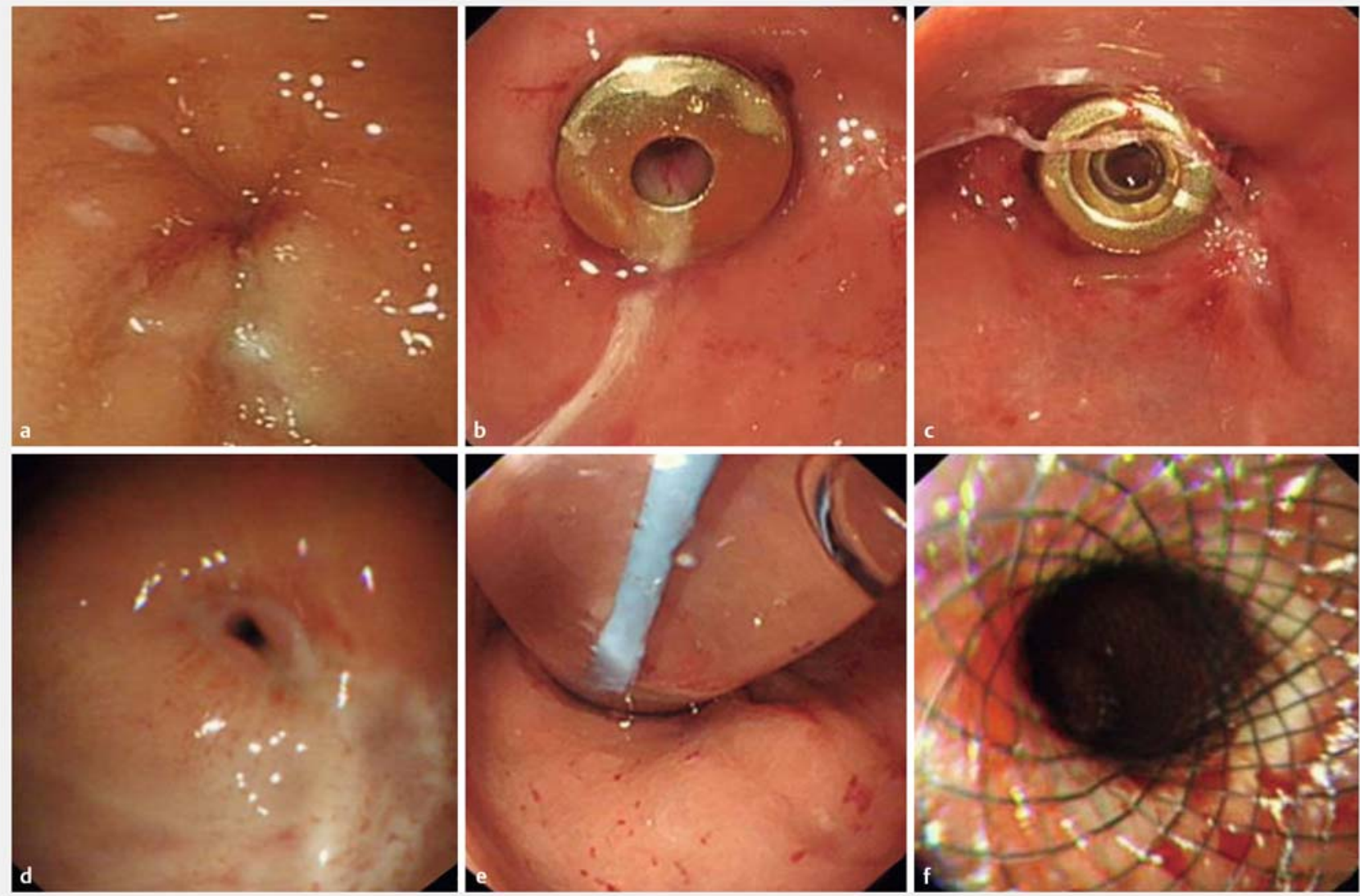

- Fig. 3 Re-formed atresic rectal anastomotic stoma, treated by repeat magnetic compression anastomosis and balloon dilatation followed by stent implantation. a Atresic anastomotic stoma. $\mathbf{b}, \mathbf{c}$ Magnetic rings in place: $\mathbf{b}$ on the oral side, $\mathbf{c}$ on the anal side. $\mathbf{d}$ Anastomotic stoma stenosis. e Balloon dilation. f Stent implantation.

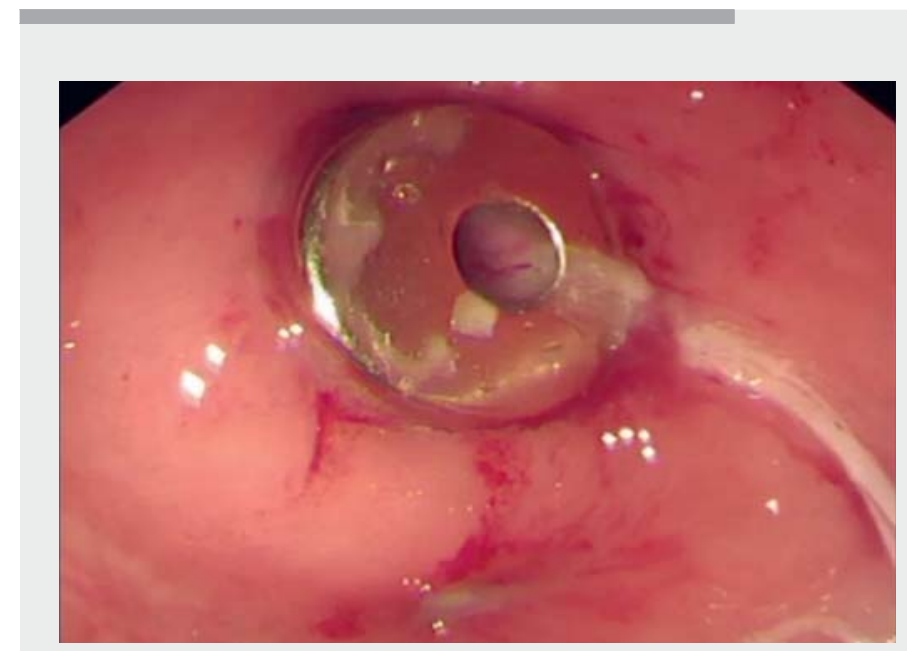

Video 1 Endoscopy-assisted rectal magnetic compression anastomosis.

length was confirmed under colonoscopy and meglumine diatrizoate radiography ( Fig. 1).

After the patient had given signed informed consent and undergone pre- operative examination and general anesthesia, endoscopy-assisted rectal MCA was performed, lasting $1.5 \mathrm{~h}$ ( $>$ Fig. 2). The enteroscope with the magnetic ring attached to it was passed in a retrograde manner from the terminal ileum to the blind end of the anastomotic stoma, where the magnetic ring was released. Then another magnetic ring was passed by hand through the anus to the anastomosis. The two magnetic rings were attracted to each other across the anastomotic stoma. Lastly, the enteroscope was removed and $\mathrm{C}$-arm radiography showed that the magnetic rings were well aligned. At 13 days after MCA, the magnetic ring complex was discharged through the anus. Anastomotic stoma recanalization with an intestinal diameter enlarged to $1 \mathrm{~cm}$ after balloon dilatation was confirmed by colonoscopy ( $>$ Fig. 2 ). After 1 month, the rectal anastomotic stoma was atresic again, and endoscopyassisted rectal MCA was again carried out; repeat anastomotic balloon dilation with subsequent stent implantation were then performed ( $\triangleright$ Fig. 3 ; $>$ Video 1 ).

Anastomotic stoma recanalization was confirmed by colonoscopy without re- 

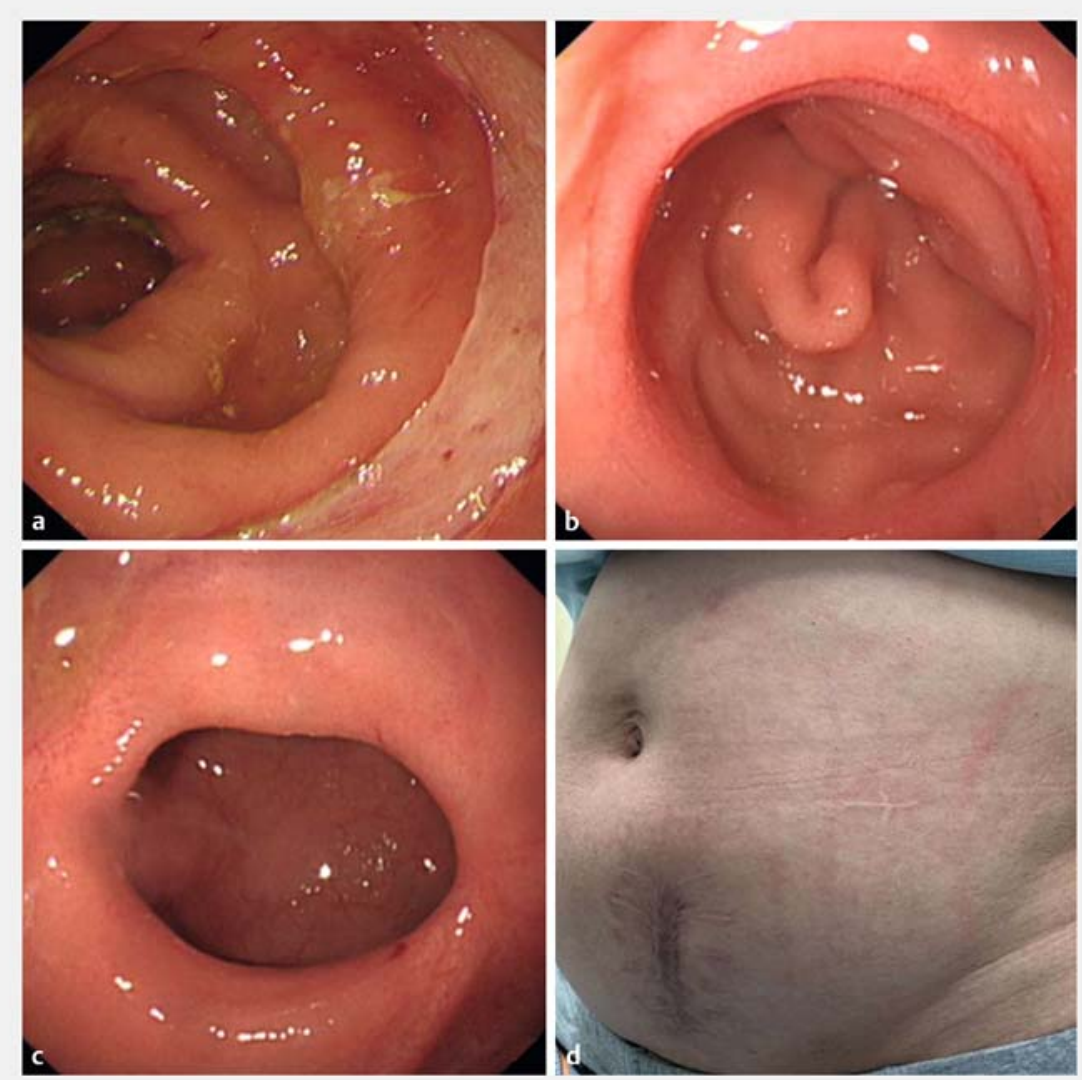

- Fig. 4 a-c Recanalized anastomotic stoma. d Patient's abdomen after stoma closure surgery.

sistance 7 months after the operation. Stoma-closure surgery has been performed, and normal transanal defecation has been restored ( $>$ Fig. 4 ).

\section{Endoscopy_UCTN_Code_TTT_1AQ_2AF}

\section{Acknowledgments}

The authors want to thank the State Key Laboratory for Mechanical Behavior of Materials, Xi'an Jiaotong University.

\section{Competing interests}

The authors declare they have no conflict of interest.
The authors

Guifang Lu', , Jing Li ${ }^{1,{ }^{*},}$ Mudan Ren ${ }^{1}$, Feng $\mathrm{Ma}^{2}$, Xuejun Sun ${ }^{3}$, Yi Lv ${ }^{4}$, Shuixiang $\mathrm{He}^{1}$

1 Department of Gastroenterology, The First Affiliated Hospital of Xi'an Jiaotong University, Xi'an, Shaanxi, P. R. China

2 National and Local Joint Engineering Research Center for Precision Surgery and Regenerative Medicine, The First Affiliated Hospital of Xi'an Jiaotong University, Xi'an, Shaanxi, P. R. China

3 Department of General Surgery, The First Affiliated Hospital of Xi'an Jiaotong

4 Department of Hepatobiliary Surgery, The First Affiliated Hospital of Xi'an Jiaotong University, Xi'an, Shaanxi, P. R. China University, Xi'an, Shaanxi, P. R. China
Corresponding author

\section{Shuixiang He, PhD}

Department of Gastroenterology, The First Affiliated Hospital of Xi'an Jiaotong University, No. 277 Yanta West Road, Xi'an, Shaanxi 710061, P. R. China dyyyjxk@mail.xjtu.edu.cn

\section{References}

[1] Jiang XM, Yamamoto K, Tsuchiya T et al. Magnetic compression anastomosis for biliary obstruction after partial hepatectomy. Endoscopy 2018; 50: E144-E145

[2] Jang SI, Choi ], Lee DK. Magnetic compression anastomosis for treatment of benign biliary stricture. Dig Endosc 2015; 27: 239249

[3] Mimuro A, Tsuchida A, Yamanouchi E et al. A novel technique of magnetic compression anastomosis for severe biliary stenosis. Gastrointest Endosc 2003; 58: 283-287

[4] Jang SI, Rhee K, Kim H et al. Recanalization of refractory benign biliary stricture using magnetic compression anastomosis. Endoscopy 2014; 46: 70-74

\section{Bibliography}

Endoscopy 2021; 53: E437-E439

DOI 10.1055/a-1322-1899

ISSN 0013-726X

published online 27.1.2021

(c) 2021. Thieme. All rights reserved.

Georg Thieme Verlag KG, Rüdigerstraße 14,

70469 Stuttgart, Germany

\section{CORRECTION}

Endoscopy-assisted magnetic compression anastomosis for rectal anastomotic atresia

Lu G, Li J, Ren M et al. Endoscopyassisted magnetic compression anastomosis for rectal anastomotic atresia. Endoscopy 2021; 53: E437E439.

In the above-mentioned article the length of the anastomotic atresia was corrected to $0.5 \mathrm{~cm}$. This was corrected in the online version on September 23 2022.

\footnotetext{
* Jing Li and Guifang Lu contributed equally to this article and are considered joint first authors.
} 